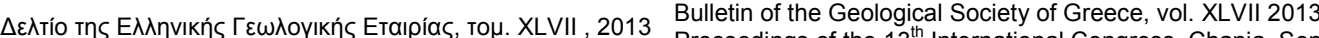
XLVII, 2013 Proceedings of the $13^{\text {th }}$ International Congress, Chania, Sept.

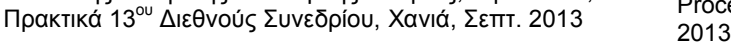

\title{
QUALITATIVE PRECURSORY PATTERN BEFORE SEVERAL STRONG EARTHQUAKES IN GREECE
}

\author{
Baskoutas I. ${ }^{1}$ and Papadopoulos G. ${ }^{2}$ \\ ${ }^{1}$ Institute of Geodynamics, National Observatory of Athens, Greece.Email: i.baskoo@noa.gr \\ ${ }^{2}$ EPPO, Seismotect.Div.,Xanthou32,15451.Athen,Greeces.Email: gpapadopoulos@oasp.gr
}

\begin{abstract}
The temporal variation of the seismicity, based on the analysis of three seismic parameters i.e., number of earthquakes, b-value and energy released, were investigated before several strong earthquakes occurrence in Greece the time period 2000-2008. The seismic parameters estimates were obtained by the means of new tool, suited to analyze earthquake catalogue, and visualize their spatio-temporal variation behaviour. The seismic data used were taken from the earthquake catalogue of the Geodynamic Institute of National Observatory of Athens, Greece. The obtained temporal variation series shows significant changes around their relative mean values, which specific phases can be related to the strong earthquakes preparation stages. This relation shows remarkable temporal regularity so that it can be establish considered as a precursor seismicity pattern. These results suggest that identification of this behaviour, by the continuous monitoring of the temporal variation of the seismic parameters, can contribute to the assessment of the current seismic hazard and to the impending strong earthquake parameters evaluation, in a given area.
\end{abstract}

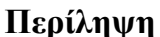

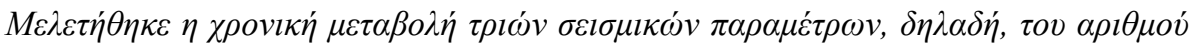

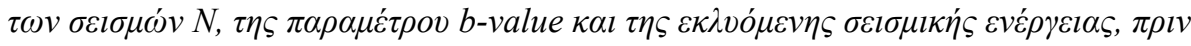

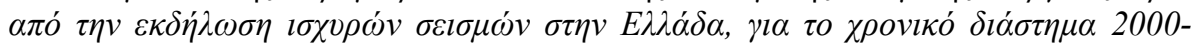

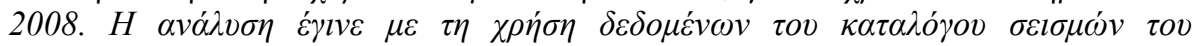

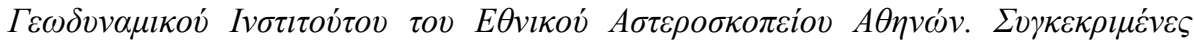

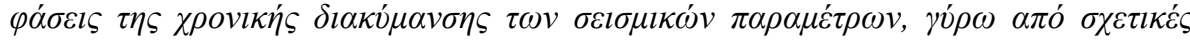

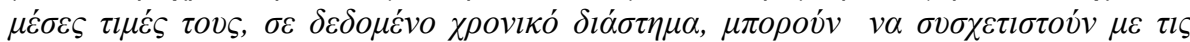

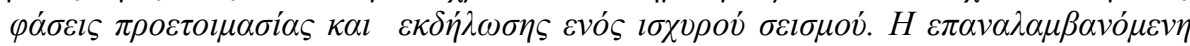

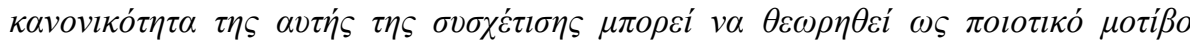

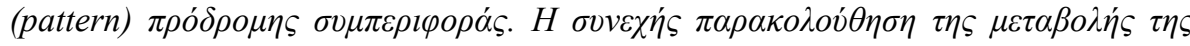

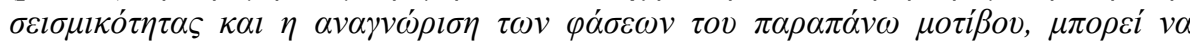

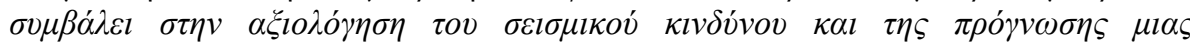

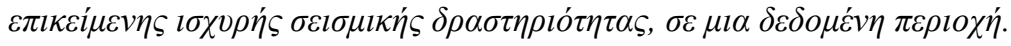

Keywords: Seismic energy released, b-value, temporal variation of seismicity, precursory seismicity pattern. 


\section{Introduction}

Precursory seismicity changes have attracted the attention of researchers over the years and several types of patterns preceding large earthquakes have been proposed worldwide, including preseismic activation, quiescence, clustering, earthquake migration and combinations of these. In the overwhelming majority, the study of these precursory patterns were based mainly on the statistical analysis or the spatiotemporal characteristics of the seismicity (Habermann, 1981; Kanamori H., 1981; Caputo et. al., 1983; Papadimitriou and Papazachos 1985; Matthews and Reasenberg, 1988; Eneva and Hamburger, 1989; Shaw, et al., 1992; Romanowicz, 1993; Kossobokov and Carlson, 1995; Press and Allen, 1995; Shebalin et al., 2000; Di Giovambatista and Tyupkin, 2000; KeilisBorok, et al., 2002; Papadopoulos et al., 2002; Tiampo et al.; 2002; Papadopoulos et al., 2003; Zavyalov, 2003; Papazachos et al., 2004; Baskoutas et al., 2004; Matsumura, 2006; Sobiesiak, et al., 2007; Papadimitriou P., 2008).

Seismic precursors may reflect changes in rock properties connected with the earthquake preparatory process, but the results obtained in the identification of these precursors may differ, in size and shape, depending on differences in experimental method or regional characteristics and can be interpreted in different ways. Alternatively, such precursors may result from systematic spatio-temporal seismicity fluctuations in areas of spatially varying rock properties. In this direction, Papadopoulos and Baskoutas (2003; 2009; 2011) have introduced the FastBEE algorithm for the seismic hazard assessment, base on the hypothesis that temporal changes of the seismicity reflects the influence of the physical process. The analysis tool, in this algorithm, was designed to obtain temporal variation profiles of some basic seismicity parameters, by the elaboration of common earthquake catalogue data. The retrospective application of this algorithm (Baskoutas et al., 2004; Baskoutas et al., 2011; Papadopoulos and Baskoutas, 2011) has shown that the obtained temporal variation profiles, over a long time interval, present a clear precursory regularity, which can be related to strong earthquake occurrence. This behaviour, introducing a new model regarding the intermediate term earthquake prediction, was interpreted (Papadopoulos and Baskoutas 2011) in term of the phases of the phenomelogical "Consolidation Model" of the earthquake preparation process, proposed by Dobrovolski (1991). Given that the geodynamic regime in the Hellenic arc and trench system controls the physical process of strong earthquakes occurrence, this paper describe the characteristic of the above mentioned precursory pattern, observed before all strong earthquakes, with magnitudes $M>6.0$ occurred in Greek territory in the time period 2000 to 2008 .

\section{Qualitative Temporal Variation Precursory Seismicity Pattern}

In applying the FastBEE tool analysis, the temporal variation series of the seismic parameters estimates were obtained by a simple moving-window technique, with one-month step. In continuation the smoothed estimates were filtered, with the same width filter, in order to avoid side lobs effect. This procedure makes the temporal changes, with periods equal or greater of the half filter width, to pass undistorted. The final output includes the temporal variation of all three examined seismic parameters, which each one appears as a complex of two superposed curves, (figure 3). The first thin violet curve represents the smoothed time series and the second bolder red line the filtered one. The standard errors for the $b$-value and the confidence limit $1 \sigma$ of the parameters $\log \mathrm{N}$ and $\log \mathrm{E}^{2 / 3}$, in the same graph can be seen as lines parallel to their mean values in the examined time period. The observed clear fluctuation of all parameters, over and above their relative mean values, forms consecutive relative minima and maxima. These changes, although their qualitative characters are believed to reflect the changes in stress in the broader area. The positive relation of the observed significant fluctuations with strong earthquakes occurrence were considered by Papadopoulos and Baskoutas $(2009 ; 2011)$ as prognostic anomalies. The regularity of temporal prognostic anomalies appearance, over a long time variation profiles can be formulated, in the ambit of the FastBEE algorithm, as a qualitative precursor seismicity pattern.

$\underline{\text { XLVII, No } 3-1062}$ 
The general trend of this pattern, in all three parameters, appears schematically in the figure 1 and its characteristics can be summarized as follow:

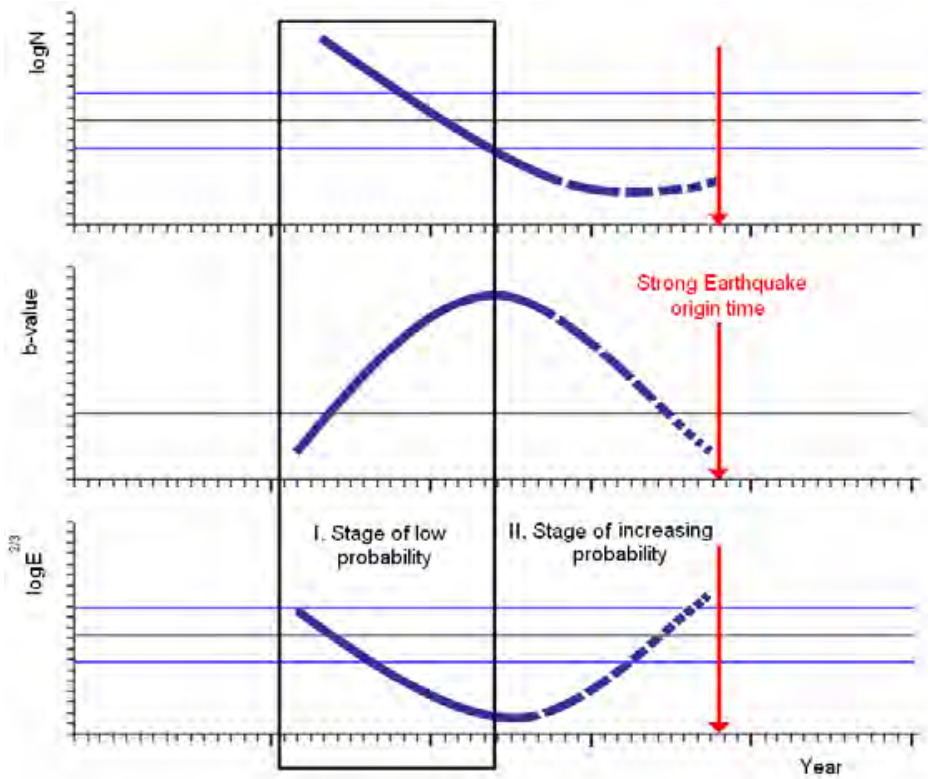

Figure 1 - Schematic representation of the temporal prognostic anomaly. Open rectangular parallelogram denotes the first, low probability stage, which is followed by an increasing probability stage. Vertical red arrow shows the earthquake origin time.

The temporal variation of the parameter $\operatorname{logN}$, shows, in the majority of the cases a clear decreasing phase toward to the relative mean value, in the examined time interval and bellow to the confidence level of $70 \%$, reaching to a relative minimum. Usually the relative mean values, especially when the examined time interval is long enough, some how represent the background ("normal') seismicity in a given region and the previously decreased stage denote kind of "quiescence" period. This parameter usually reflects the fluctuation of the number of earthquakes despite the present of a strong earthquake. In case of strong earthquake occurrence the influence of its aftershock activity can add information of the evaluation of the two other considered seismic parameters. Nevertheless it was found that the use of a declustered, for aftershocks, earthquake catalogue doesn't change the qualitative character of the observed precursory seismicity pattern.

Parameter b-value, in the same pattern, shows at the beginning an increasing trend until it reaches a relative maximum. After that this parameter starts to decreases constantly toward to the relative mean value and even lower. Usually the strong earthquake occurrence falls within this time interval. Finally the parameters $\log \mathrm{E}^{2 / 3}$, contrary to the $\mathrm{b}$-value, is characterized by a gradual decrease toward to the relative mean value and even lower to the confidence limit. The inversion of this trend to toward to the mean value, signalize the impending strong earthquake occurrence.

It was observed that the temporal evolution of the foresaid prognostic anomaly can be divided in two distinct probability stages. During the time evolution of the first period the probability for a strong earthquake occurrence is very low; contrary the second period the probability for a earthquake occurrence is high, which become higher, as the temporal anomaly is approaching to its end and no earthquake is yet occur (dashed line in figure 1).

Previous studies have shown that among all three examined seismic parameters, $b$-value and the seismic energy releases, in the form $\log \mathrm{E}^{2 / 3}$, are more informative in respect to the parameter $\log \mathrm{N}$, although this last can add information when anomalous temporal variation appears in the 
seismicity of the region. From the physical point of view, the quantity $\log E^{2 / 3}$, is proportional to the rate of accumulation of the dynamic ruptures in the strong earthquakes preparation process area, (Keilis-Borok 1959; Sadowski \& Pisarenko, 1983) reflecting the variations of the tectonic stress in the region of the observation. For this reason, parameter $\log E^{2 / 3}$ seems to describe much better the observed temporal variation of the seismicity, due to the temporal changes of the stress field influence precursory seismicity pattern case studies before several strong earthquakes in Greece.

\section{Precursory Seismicity Pattern Before Several Strong Earthquakes in Greece.}

Earthquakes, with magnitude $\mathrm{Ms} \geq 6.0$ in Greek territory, represents according to Papazachos and Papazachou (2003), the lower magnitude of a destructive earthquake with a return period of about one year. For this reason all events above this magnitude threshold, in the time period 2000-2008 were investigated in relation to the observed foresaid temporal variation anomaly. The seismic data used was taken from the Earthquake Catalogue of the Geodynamic Institute, of the National Observatory of Athens (NOA), Greece. Table 1 show the parameters of the examined strong earthquakes and figure 2 shows their epicentres, numbered according to the serial numbers of the Table 1.

The Skyros 2001, July 26, with $\mathrm{Ms}=5.8$ earthquake, although smaller than the defined threshold (nevertheless reported by NEIC, as $\mathrm{M}=6.5$ ), was included in this study, because it belongs to a remarkable strong earthquake activity of a cluster of eight (8) events, with magnitude $\mathrm{Ms} \geq 5.5$, which have been occurred within the short time interval of 14 hours (Table 2).

Table 1 - Earthquakes catalogue parameters with magnitude $M_{S} \geq 6.0$, in the time period 2000-2008.

\begin{tabular}{|l|l|l|l|l|l|l|l|}
\hline s/s & Date & $\begin{array}{l}\text { Orig } \\
\text { Time }\end{array}$ & Lat & Lon & Depth & $\begin{array}{l}\text { Magn } \\
\text { GINOA }\end{array}$ & Magn NEIC \\
\hline 1 & 2001 JUL 26 & $00: 21$ & 39.06 & 24.24 & 10 & 5.8 & 6.5 MwGS \\
\hline 2 & 2003 AUG 14 & $05: 14$ & 38.79 & 20.56 & 12 & 6.4 & 6.3 MwHRV \\
\hline 3 & 2005 OCT 17 & $05: 45$ & 38.13 & 26.59 & 29 & 6.0 & 5.5 MwHRV \\
\hline 4 & 2005 OCT 18 & $15: 25$ & 37.58 & 20.86 & 22 & 6.1 & 5.7 MwHRV \\
\hline 5 & 2007 MAR 25 & 1357 & 38.34 & 20.42 & 15 & 6.0 & 5.7 MwGS \\
\hline 6 & 2008 FEB 14 & 1009 & 36.50 & 21.78 & 41 & 6.7 & 6.9 MwGCMT \\
\hline 7 & 2008 JUN 8 & 1225 & 37.98 & 21.51 & 25 & 7.0 & 6.4 MwGCMT \\
\hline 8 & 2008 JUL 15 & 0326 & 35.85 & 27.92 & 56 & 6.7 & 6.4 MwGCMT \\
\hline 9 & 2008 OCT 14 & 0206 & 38.85 & 23.62 & 24 & 6.1 & 5.2 MwGCMT \\
\hline
\end{tabular}

The temporal variation of the seismicity, before each strong earthquake is based on the elaboration of a seismic data set for a period of ten years within a rectangular area around the earthquake epicenter and with size of $100 \times 100 \mathrm{Km}$. Figure 3 shows, as an example, the characteristic FastBEE output, with the seismic parameters temporal variation, for the Skyros 2001 earthquake. The inspection of this figure shows the characteristic temporal behaviour of the previously described "prognostic anomaly". The curve of the parameter $\log \mathrm{N}$ starts to decrease continuously after the middle of the year 1998, when it crosses the relative mean value. This behaviour somehow depicts a "quiescence period". In the same time interval curves of the parameters b-value and $\log \mathrm{E}^{2 / 3}$, start to increase and decrease respectively, signalizing the first, low probability for an earthquake occurrence, stage (see also figure 1), and lasting till the middle of the year 1999, where both reach

XLVII, No $3-1064$ 
their respective relative maximum and minimum. After this date starts the beginning of the second stage high probability stage, which becomes critical in the middle of 2000 and especially when the $\log \mathrm{E}^{2 / 3}$ parameter crosses the lower confidence limit $(70 \%)$ line concluding with the strong earthquake occurrence one year later (July 26, 2001).

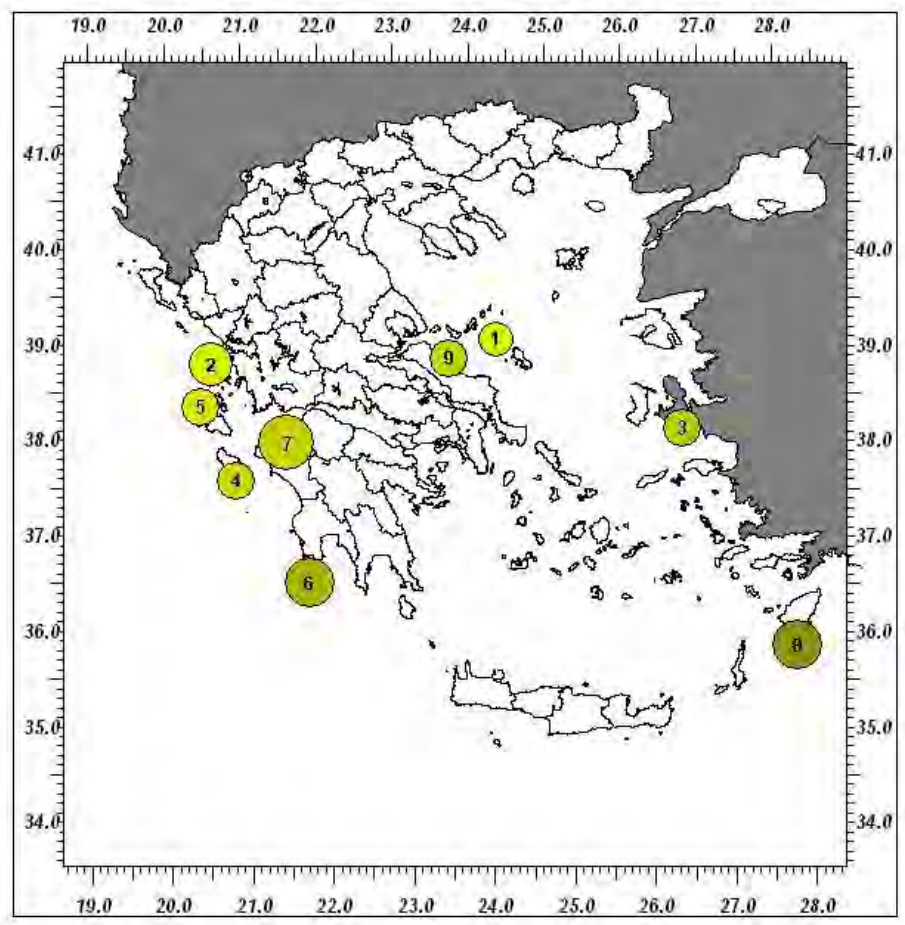

Figure 2 - Map of seismic epicenters of the shallow strong earthquakes with magnitude $M_{S} \geq 6.0$, in the time period 2000-2008.

Table 2 - List with the parameters of the Skyros, July 26, 2001 mainshock and the aftershocks with magnitude $M_{s} \geq 5.0$ (Catalogue of Geodynamic Institute of National Observatory of Athens).

\begin{tabular}{|c|c|c|c|c|c|c|}
\hline & Date & hh:mm & Lat & Lon & Depth & Magn \\
\hline 1 & 2001 JUL 26 & $00: 21$ & 39.06 & 24.24 & 10 & 5.8 \\
\hline 2 & 2001 JUL 26 & $00: 34$ & 39.04 & 24.35 & 18 & 5.3 \\
\hline 3 & 2001 JUL 26 & $02: 01$ & 39.10 & 24.31 & 21 & 5.0 \\
\hline 4 & 2001 JUL 26 & $02: 06$ & 38.96 & 24.45 & 23 & 5.2 \\
\hline 5 & 2001 JUL 26 & $02: 09$ & 38.92 & 24.52 & 24 & 5.3 \\
\hline 6 & 2001 JUL 26 & $02: 40$ & 38.97 & 24.57 & 5 & 5.1 \\
\hline 7 & 2001 JUL 26 & $04: 53$ & 39.06 & 24.38 & 22 & 5.1 \\
\hline 8 & 2001 JUL 26 & $14: 24$ & 39.11 & 24.27 & 5 & 5.1 \\
\hline
\end{tabular}

Figure 4 shows the temporal course of the "prognostic anomaly", for the Skyros 2001 earthquake, as it regards the parameter $\log \mathrm{E}^{2 / 3}$ and its polynomial fitting line (red line). The regression equation and the respective R-squared value follow as:

$$
y=1^{-06} x^{2}-0,089 x+16 \text { and } R^{2}=0,67
$$

$\underline{\text { XLVII, No } 3-1065}$ 


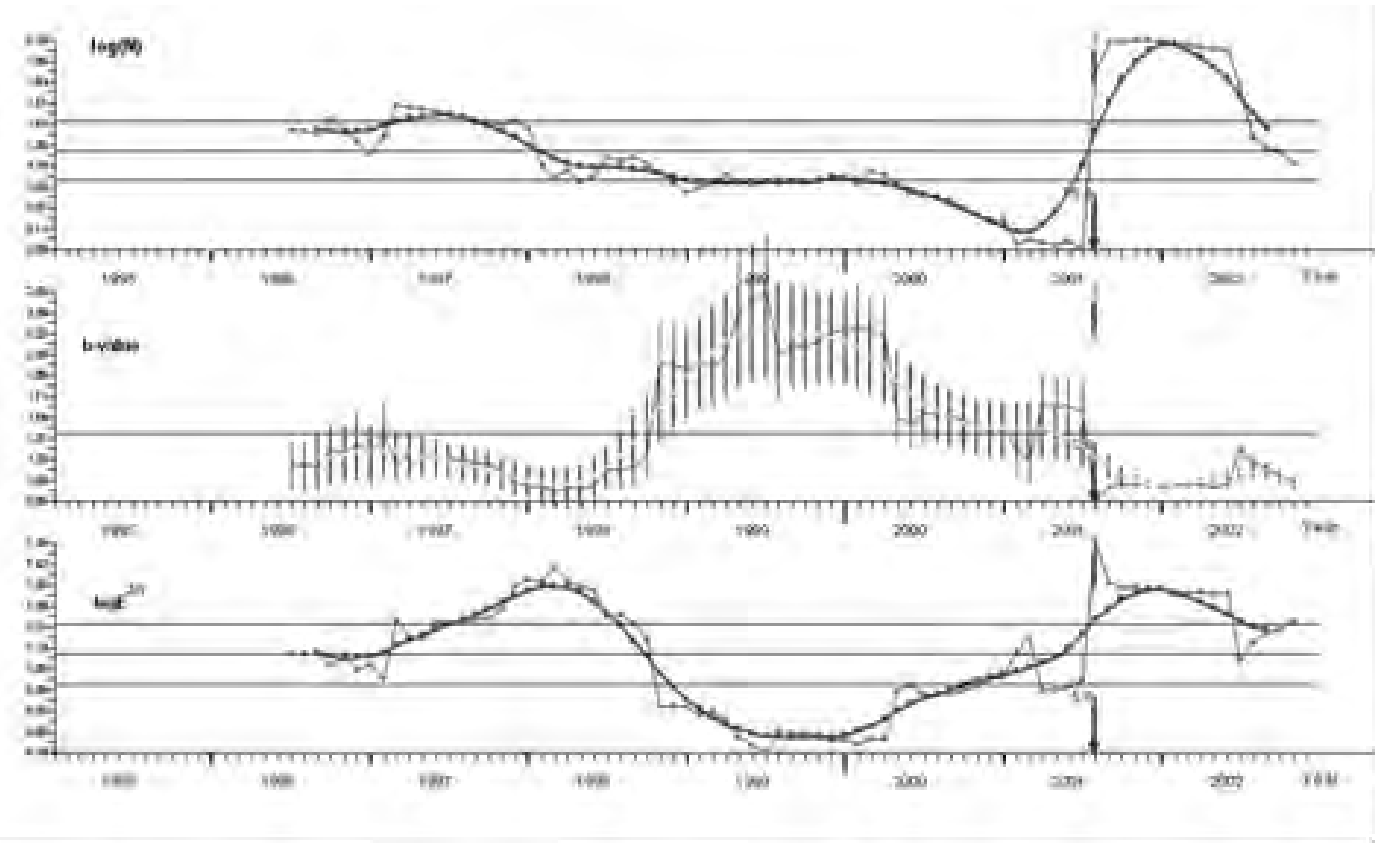

Figure 3 - Temporal variation of the seismic parameters $\log N(t)$, b-value and $\log E^{2 / 3}$, with their respective standard errors, for the Skyros 2001 July 26, Ms=5.8 strong earthquake. The numbered arrow perpendicular to the time axis denotes the earthquake origin time.

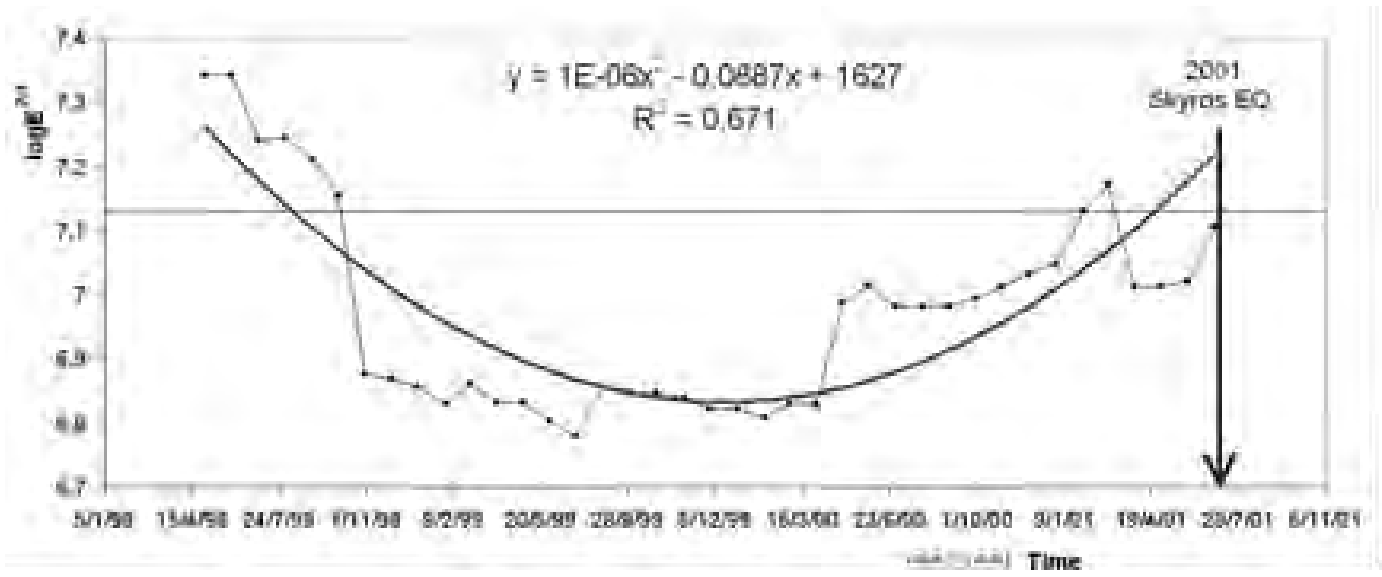

Figure 4. Prognostic anomaly for the Skyros 2001 July 26, Ms=5.8 earthquake and the respective polynomial fitting line (red line).

In the same way were obtained the prognostic anomalies, before all examined strong earthquakes, which shape, duration and their respective polynomial fitting line can be seen in the figure 5 . The regression equations and their respective R-squared values for all cases are reported in table 3 . The mean polynomial equation is:

$$
\log E=2,01^{-01} t^{2}-8,13^{-02} t
$$

Table 3 shows also the "prognostic anomaly" duration in months and the respective magnitudes of the examined strong earthquakes. Its mean duration is equal as $45 \pm 28$, ranging between a minimum of 17 and maximum of 73 months. Figure 6 shows the dependence of the "prognostic anomaly" total duration, measured form the parameter $\log \mathrm{E}^{2 / 3}$ and the magnitude. This relation 
shows a slight proportionality, with significant, in some cases, deviation around the same order of magnitude and is expressed by the following linear regression equation:

$$
\mathrm{T}_{\text {Dur }}=28,056 \mathrm{Ms}-140,3
$$

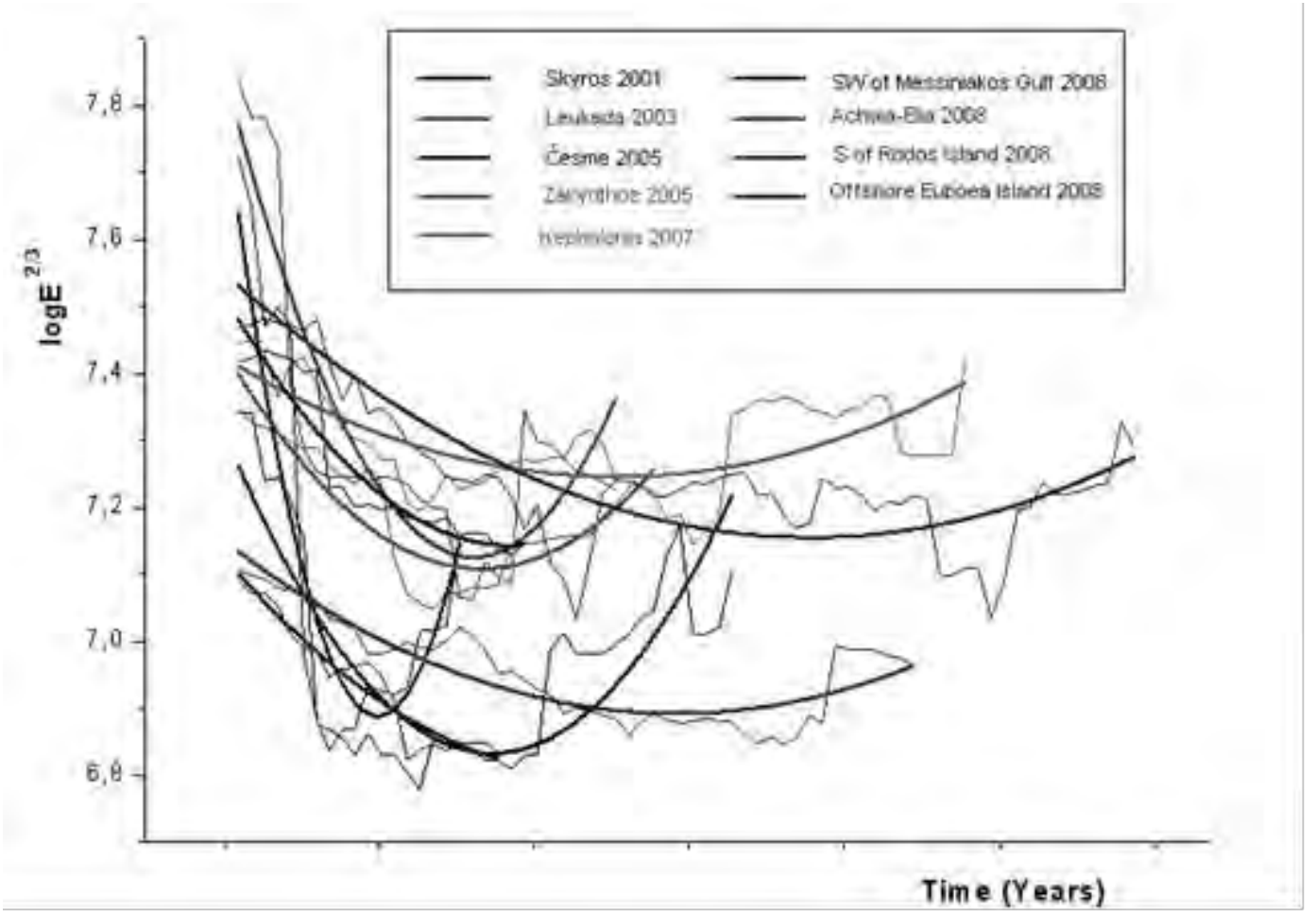

Figure 5 - The shapes and the durations of the seismic parameter $\log \mathrm{E}^{2 / 3}$ prognostic anomalies for each examined strong earthquake and their respective polynomial fitting.

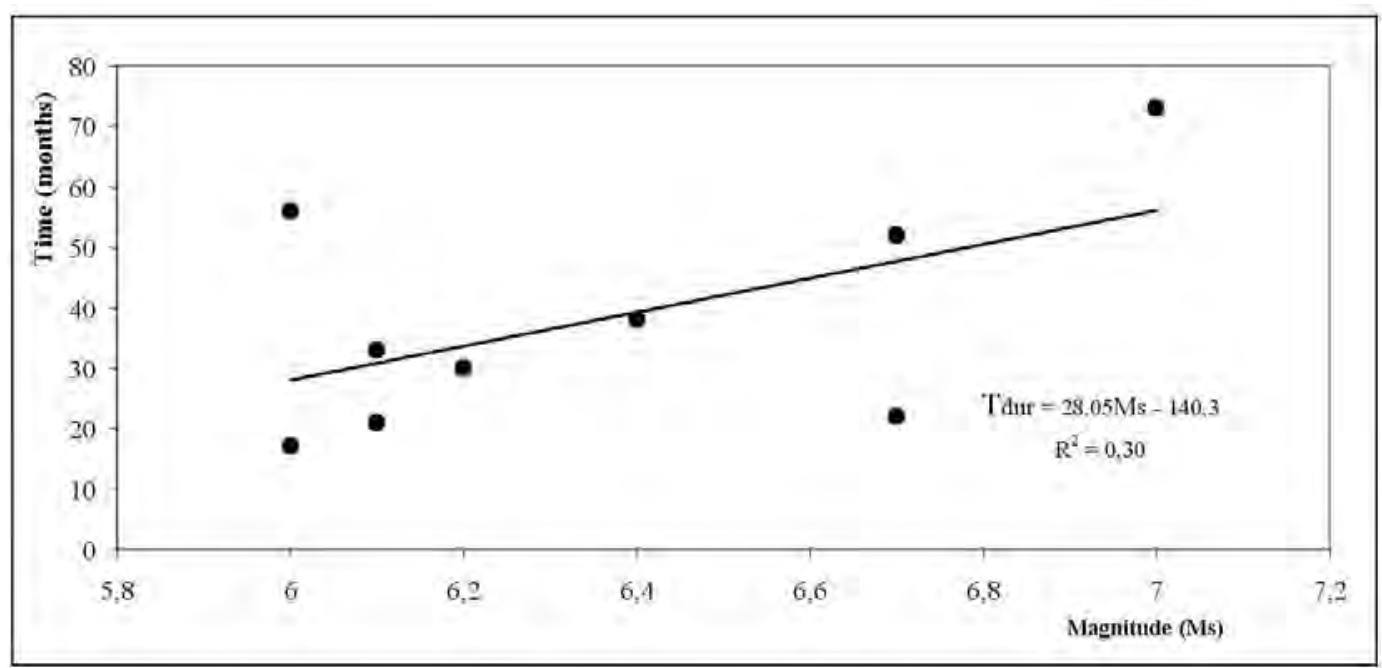

Figure 6 - The dependence between magnitude of the examined strong earthquakes and total duration of the prognostic anomaly measured in the parameter $\log \mathrm{E}^{2 / 3}$. 
Table 3. The duration of the prognostic anomalies, in the parameter $\log \mathrm{E}^{2 / 3}$ temporal variation and the magnitudes of the examined cases. (Magnitudes were taken from the catalog of Geodynamic Institute of National Observatory of Athens)

\begin{tabular}{|l|l|c|l|l|}
\hline & Case of earthquake & $\begin{array}{c}\text { Prognostic } \\
\text { anomaly } \\
\text { duration } \\
\text { (in months) }\end{array}$ & Regression Equation & $\mathbf{R}^{\mathbf{2}}$ \\
\hline 1 & Skyros 2001 & 38 & $\mathrm{y}=1^{-06} \mathrm{x}^{2}-0,09 \mathrm{x}+16$ & 0,67 \\
\hline 2 & Leukada 2003 & 30 & $\mathrm{y}=2^{-06} \mathrm{x}^{2}-0,17 \mathrm{x}+32$ & 0,78 \\
\hline 3 & Cesme 2005 & 17 & $\mathrm{y}=9^{-07} \mathrm{x}^{2}-0,069 \mathrm{x}+13$ & 0,80 \\
\hline 4 & Zante 2005 & 33 & $\mathrm{y}=2^{-07} \mathrm{x}^{2}-0,016 \mathrm{x}+32$ & 0.42 \\
\hline 5 & Kephalonia 2007 & 56 & $\mathrm{y}=8^{-07} \mathrm{x}^{2}-0,06 \mathrm{x}+13$ & 0,89 \\
\hline 6 & S Messiniakos 2008 & 22 & $\mathrm{y}=2^{-07} \mathrm{x}^{2}-0,02 \mathrm{x}+32$ & 0,70 \\
\hline 7 & Rodos 2008 & 73 & $\mathrm{y}=2^{-07} \mathrm{x}^{2}-0,02 \mathrm{x}+32$ & 0,70 \\
\hline 8 & Achaia Elia 2008 & 52 & $\mathrm{y}=2^{-06} \mathrm{x}^{2}-0,16 \mathrm{x}+31$ & 0,90 \\
\hline 9 & Evia 2008 & 21 & $\mathrm{y}=4^{-07} \mathrm{x}^{2}-0,03 \mathrm{x}+68$ & 0,93 \\
\hline
\end{tabular}

\section{Discussion and Conclusions}

The temporal variation analysis of a set of three seismicity parameters, with FastBEE algorithm, was performed in Greek territory in the time period 2000-2008. The prognostic anomaly observed before all examined strong earthquakes establish a precursory pattern, which characteristics, as it regards the parameters $\log \mathrm{E}^{2 / 3}$ were expressed in term of a polynomial fitting equation. The duration of such qualitative precursory anomalies shows a slight proportionality with the earthquake magnitude and varies, from case to case, between 17 and 73 months. The obtained theoretical polynomial prediction curves can be divided in two distinct and can be recognizable as low and high probability periods. In all examined cases, the earthquake occurrence falls within the second high probability period and especially in its later stage. It is obvious that this probability increases more and more, as this anomaly is reaching to its end and no earthquake has occurred yet Nonetheless, the earthquake occurrence can be observed in the earlier stage of this second high probability period or it can be delayed. This behaviour is an additional evidence of the influence of the geodynamic field regime acting in the wider area together with the geotectonic environment features. These factors can accelerate or delay the earthquake occurrence, although we don't know exactly how.

The result suggests that, by the constant monitoring the temporal variation of some basic seismicity parameters, in a given area and the identification of the seismic precursory pattern, can contribute to the assessment of the current seismic hazard. As a consequence the evaluation of the time evolution and the recognition of the periods of low and high probability stages can act as an alarm for an impending strong earthquake occurrence.

\section{References}

Baskoutas I., Papadopoulos G. and Panopoulou G. 2004. Long temporal variation of seismic parameters for seismic patterns identification in Greece, Bull. Geol. Soc. Greece, XXXVI/3, 1362-70. Available online at: http://geonet.geo.auth.gr/ege2004/articles/SE23 251.pdf 
Baskoutas I., Papadopoulos G. and Chingtham Pr. 2011. Temporal variation of seismic parameters in the western part of the India-Eurasia Plate Collision Zone, Research in Geophysics, 1(1). doi:10.4081/rg.2011.e3

Dobrovol'skii I. P. 1991. Theory of Preparation of a Tectonic Earthquake, Moscow, Inst. of the P hys. of the Earth, RAS, Publications.

Jenkins G.M. 1970. Time Series Analysis: Forecasting and Control. Ed.Holden Day, San Francisco. Available online at: http://www.mendeley.com/research/time-series-analysisforecasting-and-control-third-edition/

Caputo R., Console A., Gabrielov M., Keilis-Borok V.I. and Sidorenko T.V. 1983. Long-term premonitory seismicity patterns in Italy, Geophys. J. R. Astron. Soc., 75, 71-75, doi: 10.1111/j.1365-246X.1983.tb01913.x

Eneva M. and Hamburge, M.W. 1989. Spatial temporal patterns of earthquake distribution in Soviet central Asia: application of pair analysis statistics, BSSA, 79(4), 1457-76.

Di Giovambattista R. and Tyupkin Yu.S. 2000. Spatial and temporal distribution of seismicity before the Umbria-Marche September 26, 1997 earthquakes, Journal of Seismology, 4(4):589598.

Habermann R. E. 1981. Precursory seismicity patterns: Stalking the mature seismic gap. In Earthquake Prediction: An International Review (eds) Simpson, D. W., and Richards, P. G., American Geophysical Union, Washington, D.C., 29-42.

Kanamori H. 1991.The nature of seismicity patterns before large earthquakes. In: Earthquake Prediction: An International Review (eds) Simpson, D. W., and Richards, P. G., American Geophysical Union, Washington, D.C., 1-19.

Keilis-Borok V.I. 1959. On Estimation of the Displacement in An Earthquake Source and of Source Dimensions, Ann Geofis., 12, 205-214.

Keilis-Borok V., I., Shebalin P.N. and Zaliapin I.V. 2002. Premonitory patterns of seismicity months before a large earthquake: five case histories in Southern California, Proc. Natl. Acad. Sci. USA, 99(26), 16562-67.

Kossobokov V. G., Carlson J. M. 1995. Active zone size versus activity: A study of different seismicity patterns in the context of the prediction algorithm M8, J. Geophys. Res., 100(B4), 6431-41.

Matsumura S. 2006. Preparatory process reflected in seismicity-pattern change preceding the $M=7$ earthquakes off Miyagi prefecture, Japan, Earth Plan Space, 58(12), 1581-86.

Matthews M. V. and Reasenberg P. A. 1988. Statistical methods for investigating quiescence and other temporal seismicity patterns, PAGEOPH, 126(2-4), 357-372.

Papadimitriou E. E. and Papazachos B. C. 1985. Evidence for precursory seismicity patterns in the Ionian islands (Greece), Earth. Pred. Res., 3, 95-103.

Papadimitriou P. 2008. Identification of seismic precursors before large earthquakes: Decelerating and accelerating seismic patterns, J Geophys. Res., 2008, 113/ B04306, 1-19.

Papadopoulos G., Ganas A. and Plessa A. 2002. The Skyros earthquake (Mw 6.5) of 26 July 2001 and precursory seismicity pattern in the north Aegean Sea, BSSA, 92(3),1141.

Papadopoulos G., Baskoutas I. and Stavrakakis G. 2003.Tools for the Fast Estimation of Expected Big Earthquake in predefined seismic prone areas, $I^{\text {th }}$ International Workshop on Earthquake Prediction, Athens, Greece.

Popandopoulos G. A. and Baskoutas I. 2011. Regularities in the Time Variations of the Seismic Parameters and Their Implications for Prediction of Strong Earthquakes in Greece, Izv Akad Nauk. Fiz Zemli, 11, 1-12.

Papadopoulos G. A. and Baskoutas I. 2009. New tool for the temporal variation analysis of seismic parameters, Nat. Hazards Earth Syst. Sci., 9, 859-64.

Papazachos B.and Papazachou K. 2003. Earthquakes of Greece, Thessaloniki, Greece, Ziti Publications, $412 \mathrm{pp}$.

Press F. and Allen C. 1995. Pattern of seismic release in the Southern California region, J. Geophy s. Res.,100(B4), 6421-30. 
Romanowicz B. 1993. Spatiotemporal patterns in the energy-release of great earthquakes, Science, 260, 1923-1926.

Shaw B. E., Carlson J. M. and Langer J. S., 1992. Patterns of seismic activity preceding large earthquakes, J. Geophys. Res., 97, 479-89.

Shebalin P., Keilis-Borok V. I., Gabrielov A., Zaliapin I. and Turcotte D. 2006. Short-term earthquake prediction by reverse analysis of lithosphere dynamics, Tectonophysics, 413(1-2), 63-75.

Sadovski M. A. and Pisarenko V. F. 1983. On the Dependence of the Duration of Earthquake Preparation on its Energy, Dokl. Akad. Nauk SSSR, 272(2), 330-333.

Sobiesiak M. and Clark S. A. 2007. Levander A, Palma, M, Romero G. Seismicity pattern and first b-value mapping of the Caribbean - South American plate boundary in North-eastern Venezuela, American Geophysical Union. Available online at: http://adsabs.harvard.edu/abs/2007AGUSM.S33A..07S

Tiampo K. F., Rundle J. B., McGinnis S. A. and Klein W. 2002. Pattern Dynamics and Forecast Methods in Seismically Active Regions, PAGEOPH, 159(10), 2429-67.

Zavyalov A. D. 2003. Map of Expected Earthquakes in Greece for the 1996-2002 Period: Predicti on and Realization, Izvestiya, Physics of the Solid Earth, 39(1),1-6. 